\title{
Development and Testing of a Sorbent-Based Atmosphere Revitalization System for the Crew Exploration Vehicle 2007/2008
}

\author{
James C. Knox \\ NASA Marshall Space Flight Center \\ David Howard \\ All Points Logistics, Inc \\ Lee Miller \\ Lee Miller Consulting
}

\begin{abstract}
The design of a Vacuum-Swing Adsorption (VSA) system to remove metabolic water and metabolic carbon dioxide from the Orion Crew Exploration Vehicle (CEV) atmosphere is presented. The approach for Orion is a VSA system that removes not only 100 percent of the metabolic $\mathrm{CO}_{2}$ from the atmosphere, but also $100 \%$ of the metabolic water as well, a technology approach that has not been used in previous spacecraft life support systems. The design and development of the Sorbent Based Atmosphere Regeneration (SBAR) system, including test articles, a facility test stand, and full-scale testing in late 2007 and early 2008 is discussed.
\end{abstract}

\section{INTRODUCTION}

In this paper we discuss a technology program aimed at developing a feasible solution for an adsorbent based swing bed system to provide both humidity and carbon dioxide control for the Orion Crew Exploration Vehicle (CEV). Initially, Orion will be used for missions to the International Space Station, and later provide transport to lunar orbit. The Orion spacecraft is extremely limited with respect to weight, power, and volume thus driving systems to new levels of efficiency while maintaining high dependability and robustness. Through this effort we are focusing on refining core regenerable atmosphere revitalization technologies, the benefits of which are realized first for Orion, then incorporated in later bases and vehicles.

Unlike on other vehicles, the VSA system is slated to not only remove $\mathrm{CO}_{2}$, but is also the sole system designated for removing and controlling humidity. Metabolic water from respiration and evaporated sweat has traditionally been removed by a condensing heat exchanger. Adsorption-based water removal systems eliminate the need for gas/liquid separators and the low temperature coolant loop; however, it places additional challenges on the VSA system. Another new concept is the use of adsorbent-based VSA in place of non-regenerable lithium hydroxide (LiOH) for carbon dioxide removal for short duration missions [1]. Size and weight reductions will be required for favorable trades with the traditional $\mathrm{LiOH}$ approach; again, advances will provide greater gains in future missions that have even more stringent resource limitations.

Adsorbents are the focus of this technology program. By definition, physical sorbents do not change upon adsorbing a molecule from a fluid stream, either geometrically (such as swelling) or chemically (as in amine reactors). Molecular sieves (also known as zeolites) are a special class of adsorbent due to their crystalline structure that provides a precise pore size and negative polar moment. Various chemical compositions and crystal types are available which have pore sizes from $3-10$ angstroms. The polar surface of the pores strongly attracts both carbon dioxide and water, which are also polar, resulting in high sorbent capacities even at low concentrations [2]. The strong attractive forces do present a challenge when desorbing water in particular, resulting in the consideration of silica gel as a bulk desiccant.

\section{OVERALL APPROACH}

SBAR is under development as a risk mitigation technology to offset risks associated with the amine core technology, under development for Orion and currently the baseline approach. The goal for SBAR is to advance the technology to a level that demonstrates a system that meets performance requirements while minimizing size and weight. If the baseline system proves to be non-useable in the Orion vehicle, the SBAR technology shall be advanced to a point where it can be adopted by the flight program and updated to a flight 
configuration with minimal cost and schedule impacts. This development entails optimizing the vacuum swing process by defining preferred sorbent materials, layering, process configuration and cycling to offer a system solution to the flight program.

Time constraints dictate use of mature core technologies for the development of this system. For the SBAR, we adopted adsorbents with demonstrated effectiveness for carbon dioxide and humidity removal and high stability at anticipated thermal regeneration temperatures. Thermal regeneration is only required infrequently, if at all, and is not part of the normal VSA process. The packaging approach uses standard pelletized adsorbents in a spring-loaded packed bed, incorporating lessons learned from the International Space Station Carbon Dioxide Removal Assembly to minimize particulate generation and prevent particle liberation. Internal layering of sorbents is used to take advantage of different adsorbent capacities for water and $\mathrm{CO}_{2}$. By using proven materials, development time and cost to reach an operational system is minimized.

Another technique employed to reduce development time is the use of mathematical models and computer simulations. A simulation tool was developed to provide guidance during the evolution of the hardware designs, significantly reducing hardware development time. Testing is crucial to the verification and enhancement of the simulation tool, in turn providing more accurate predictions to guide the subsequent design progression. The simulations developed to mature the SBAR system are described briefly below and in detail in other publications [3, 4, 5 and 6].

While the time constraints of the CEV program are addressed by the conservative approach above, it is also highly desirable to advance the state-of-the art in adsorbent-based separation systems for application to future space vehicles and bases. Issues such as robustness and efficiency are therefore being addressed on a non-interference basis with the primary SBAR goals. Development of highly optimized lattice monoliths is being pursued to eliminate particle generation, reduce pressure drop, and allow for direct thermal regeneration that will benefit loop closure applications. These developments are discussed in a companion paper [7].

\section{FULL SCALE TESTING FACILITIES}

Due to the complexity of the physical processes in a vacuum-swing adsorption process, a full-scale test program was implemented as a first priority of the SBAR program. Implementation of the full scale program entailed facility enhancements to support delivery of cabin air simulant for processing, and a vacuum system that adequately emulates space vacuum, including flow resistance of the tubing from the SBAR to the CEV bulkhead, to complete the vacuum swing process.

\section{INLET CONTROL SYSTEM}

To control the inlet carbon dioxide partial pressure, humidity, and temperature, a unit was procured from Microclimate Inc., a firm with background in climate control systems for museum display cases. The unit was then modified in-house as needed to provide the following control capabilities.

- Airflow: 10-30 scfm, accuracy of $+/-0.5 \mathrm{scfm}$

- Temperature: $65-80^{\circ} \mathrm{F}$, accuracy of $+/-1^{\circ} \mathrm{F}$

- Humidity: $40-60^{\circ} \mathrm{F}$ dew point, accuracy of $+/-$ $1^{\circ} \mathrm{F}$ dew point

- $\mathrm{CO}_{2}: 2000-8000 \mathrm{ppm}$, accuracy of $+/-150 \mathrm{ppm}$

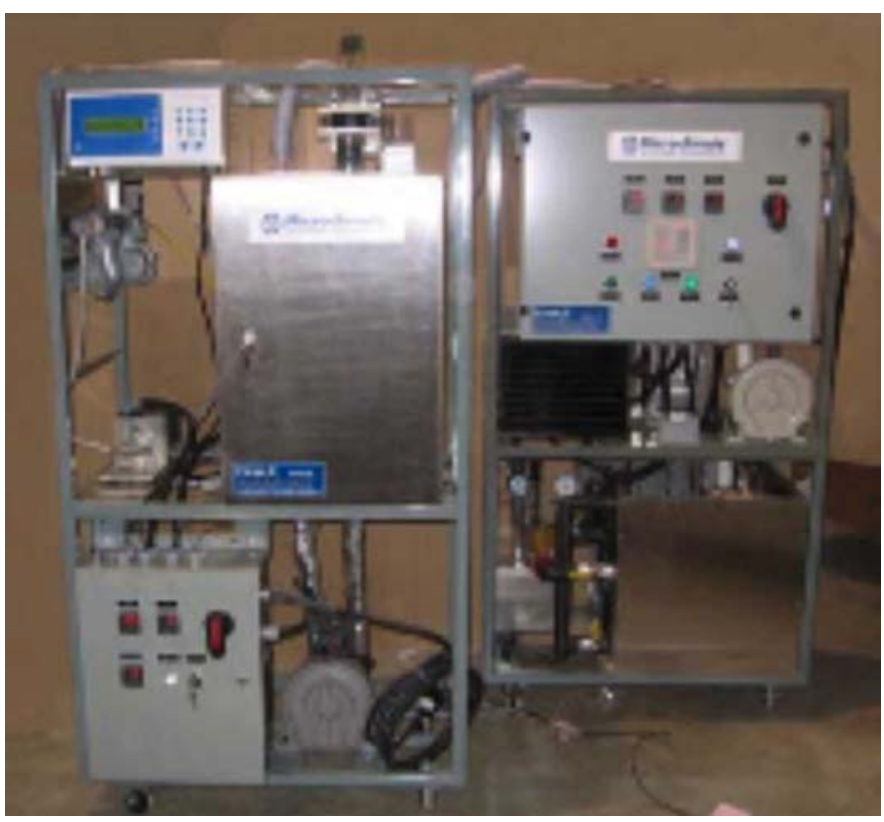

Figure 1 - Inlet Control System

The inlet control system is pictured in Figure 1. This photo was taken prior to shipment from the factory, and does not have the fluid connections in place. The righthand unit is for coarse temperature and humidity control. The left-hand unit provides final temperature and humidity control and injection of carbon dioxide.

\section{VACUUM SYSTEM DESCRIPTION}

As mentioned above, the tenacity of molecular sieves for water provides both a high capacity in adsorption, and challenge in desorption. Figure 2 presents the equilibrium adsorption capacity for water on zeolite 13X.

Data points are shown as symbols; each symbol shape provides data for a single temperature or isotherm. Lines show the adsorption isotherm correlation.

It is evident from Figure 2 that, in the absence of heating, vacuum levels well below one torr will be required for significant desorption of water from zeolite $13 X$. 


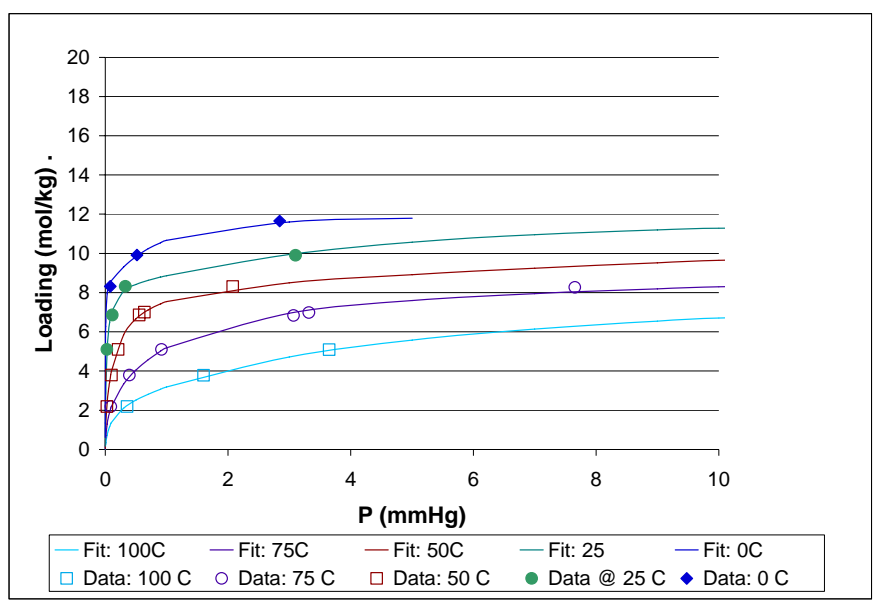

Figure 2 - Water Isotherm on Molecular Sieve 13X

The goal of the vacuum system design is to faithfully reproduce space vacuum at the simulated CEV bulkhead to SBAR interface (near the start of the sixinch vacuum line in Figure 3). The vacuum pump combines a roots pump and a sliding vane pump for high throughput and low absolute pressures. All vacuum lines, up to the SBAR interface, are $15 \mathrm{~cm}$ (6 inches) in diameter with high vacuum rated fittings. The vacuum system layout is shown Figure 3. Note that the long horizontal run has been shortened in the picture for better viewing.

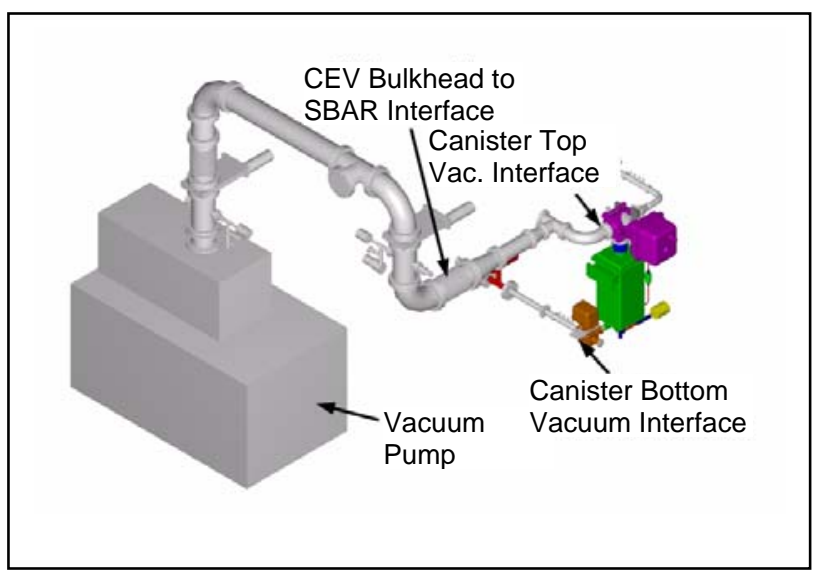

Figure 3 - Full-Scale Test Vacuum System Layout

\section{GENERAL TEST CONFIGURATION}

A schematic of the typical test configuration using the latest (phase 3) test bed is shown in Figure 4. The inlet to the sorbent canister is drawn in from the high bay and conditioned to the desired carbon dioxide and water content. Instrumentation is provided as part of the conditioning system and around the sorbent canister to record critical process measurements. A vacuum system removes carbon dioxide and water during bed desorption to simulate the vacuum of space. The internal CEV line from the sorbent canister to the CEV bulkhead is simulated with large diameter tubing. Care is taken to provide smooth transitions from the bed to the simulated 4-inch CEV bulkhead port.

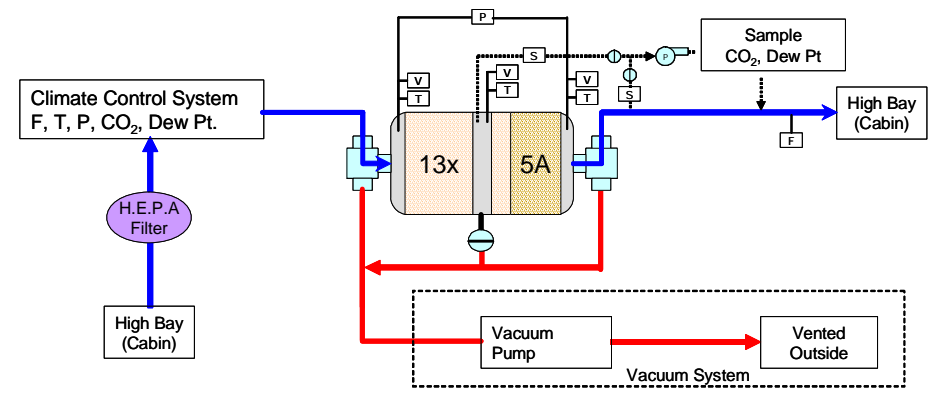

Figure 4 - SBAR Phase 3 Full Scale Test Schematic

$\mathrm{F}$ - flowmeter; $\mathrm{T}$ - thermocouple; $\mathrm{P}$ - pressure sensor; $\mathrm{CO}_{2}-\mathrm{CO}_{2}$ sensor; Dew Pt. - dewpoint sensor; V - vacuum sensor; S - sample line

\section{DATA ACQUISITION AND CONTROL}

A commercial program, National Instrument's LabVIEW, is being used for the interface with the instrumentation and for automated control of the system's valves. PACRATS, an existing MSFC program, is used to archive all instrumentation data and provide real-time monitoring capability at remote locations. This capability has proved useful for many previous ECLS tests, allowing design engineers to monitor testing real-time from their desks and provide immediate feedback to test engineers regarding anomalous data trends. An example screen shot taken during SBAR P2 testing is shown in Figure 5 . Workspaces may be built with a variety of "instruments", including plots as shown, as well as tables, meters, and lists. Workspaces are comprised of multiple panels, one of which is shown in Figure 5.

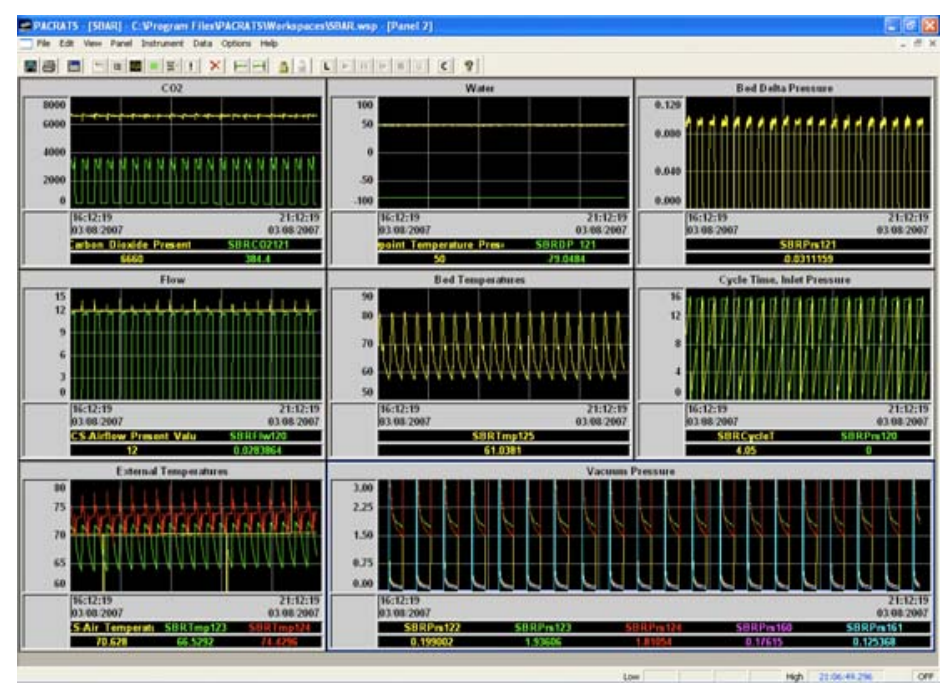

Figure 5 - PACRATS Screen Shot During SBAR Prototype 2 Testing

\section{CAPABILITY UPDATES FOR FUTURE TESTING}

Upgrades to the testing capabilities are being implemented to facilitate a new phase of testing to 
include metabolic transients and simulated suit loop conditions. The CEV configuration includes the suit loop mode of operation with all crew inside spacesuits; hoses connect them to the atmosphere revitalization system. In this mode, operations are at reduced pressures and overall volume is greatly reduced. The low pressure operation will be achieved by addition of a suction blower to reduce pressure. Metabolic transients will be simulated by performance guided feedback computer control that will adjust inlet constituents as needed. Testing with these capabilities is slated to occur this year.

\section{DEVELOPMENT TEST PHASES}

To date, SBAR has progressed through three main phases that encompass different bed configurations, sizes, and cycle timing. Lessons learned via extensive test and analysis has enabled performance increases, weight reductions, and appropriate design changes in response to dynamic system requirements. To date, we are operating in the $3^{\text {rd }}$ system design phase. The latest bed design contains three ports to vacuum and a reduced sorbent volume of $6.2 \mathrm{~L}$ per bed. This is an evolution from the initial $18 \mathrm{~L}$ bed with a single large vacuum port. A description of the various test phases, results, and analyses are described below.

\section{PHASE 1 DESCRIPTION}

A general depiction of the Phase 1 sorbent bed, associated valving, and some of the instrumentation is shown in Figure 6.

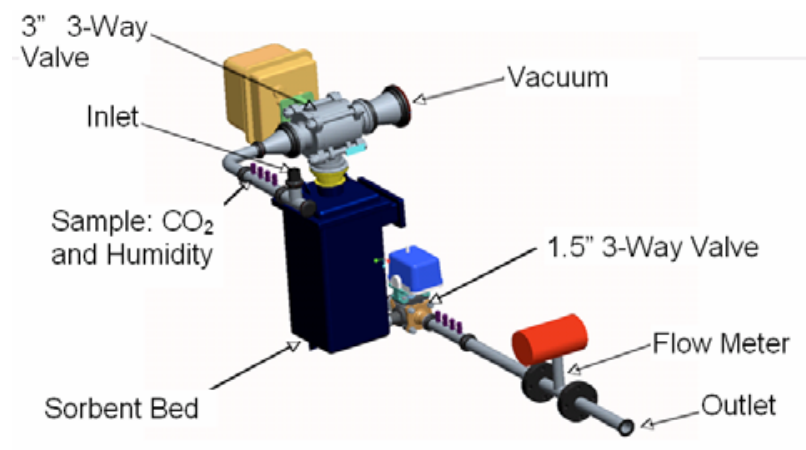

Figure 6 - SBAR Phase 1 Test Article with Supporting Hardware

The phase 1 (P1) test article consisted of a modified development International Space Station (ISS) sorbent bed fitted with commercial valves. Because flow to vacuum is imperative for performance, a gas dynamics analysis was performed and indicated the conductance of a 3-inch valve was needed to efficiently transport $\mathrm{CO}_{2}$ and $\mathrm{H}_{2} \mathrm{O}$ from the sorbent canister through the CEV vacuum lines to space vacuum. Since vacuum levels are an extremely critical aspect of the system performance, particular attention was given to pressure measurements in the bed. Packed with UOP zeolite 5A, this bed was used to provide fundamental data on the characteristics of adsorbents with high humidity loading undergoing a vacuum swing adsorption process. The data was also used to enhance computer-modeling capabilities in continuing development at the University of South Carolina (3). Phase 1 testing occurred from July to November of 2006 . Information gained from the initial test, subscale testing, and computer modeling was used to design the Phase 2 bed.

\section{PHASE 1 TEST RESULTS}

The space station prototype molecular sieve $5 \mathrm{~A}$ canister operated for a series of 14 tests of approximately 50 hours each. An initial observation showed that although the system had a large 3 inch port to vacuum at the inlet end of the bed to accommodate expelling desorbed $\mathrm{CO}_{2}$ and $\mathrm{H}_{2} \mathrm{O}$ to vacuum, the measured vacuum at the outlet end was not adequate for desorption. Computer simulations verified the existence of a pressure gradient inside the bed while under vacuum. This resulted from flow resistance of the low pressure, high velocity gasses through the bed. To lower the pressure at the outlet end and aid in desorption, a port to vacuum was added at the canister outlet. Figure 7 illustrates performance gains by adding the second port to vacuum.

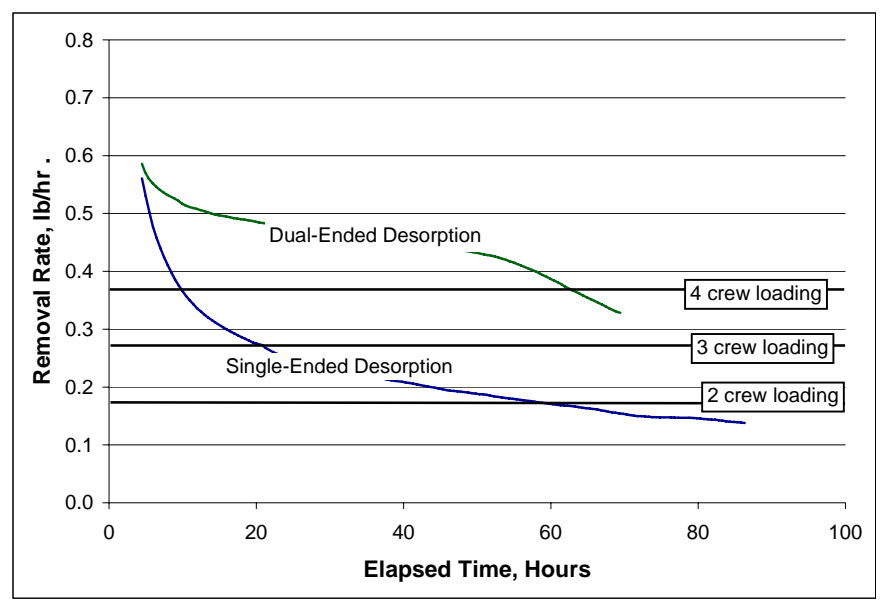

Figure 7 - Generalized Dual and Single Ended Desorption $\mathrm{CO}_{2}$ Removal History for $\mathrm{CO}_{2} / \mathrm{H}_{2} \mathrm{O}$ P1 Testing

Testing included operational variations such as;

1. Mild heating of the sorbent during desorption to counteract the endothermic process

2. Evaluating $\mathrm{CO}_{2}$ in single vs. dual ended desorption mode without the presence of water to assess coadsorption effects

3. Nine cases with a mixed inlet of $\mathrm{CO}_{2}$ and water to simulate real life loading scenarios.

In summary, adding a second port to vacuum at the bed outlet dramatically improved performance. It was found that water tends to propagate through the bed and over time the $\mathrm{CO}_{2}$ adsorption capacity is reduced. Zeolites $5 \mathrm{~A}$ and $13 \mathrm{X}$ preferentially adsorb water over $\mathrm{CO}_{2}$, and will in fact release $\mathrm{CO}_{2}$ during water adsorption. The result of this "water creep" effect, and the competitive coadsorption between $\mathrm{H}_{2} \mathrm{O}$ and $\mathrm{CO}_{2}$, is illustrated in Figure 7 by the gradual decrease of $\mathrm{CO}_{2}$ removal rate. One of 
the objectives of the SBAR program is to understand and manage the effect of water creep on $\mathrm{CO}_{2}$ removal performance.

The performance variation resulting from changes in operational configurations are shown in Figure 8. It is evident from this figure that these changes (inlet temperature variation, heating to $100^{\circ} \mathrm{F}$ during desorption, and a small reduction in vacuum pressure) had little impact on performance when compared with the change from dual-ended to single-ended desorption. To illustrate, note the large difference in removal rates from the single-ended cases (TC1, TC2, and TC12) compared with the remaining, dual-ended desorption cases. Other operational differences, such as inlet temperature (TC1 vs. TC2 and TC3 vs. TC4) and mild heating (TC4 vs. TC5), result in only minor changes in removal performance.

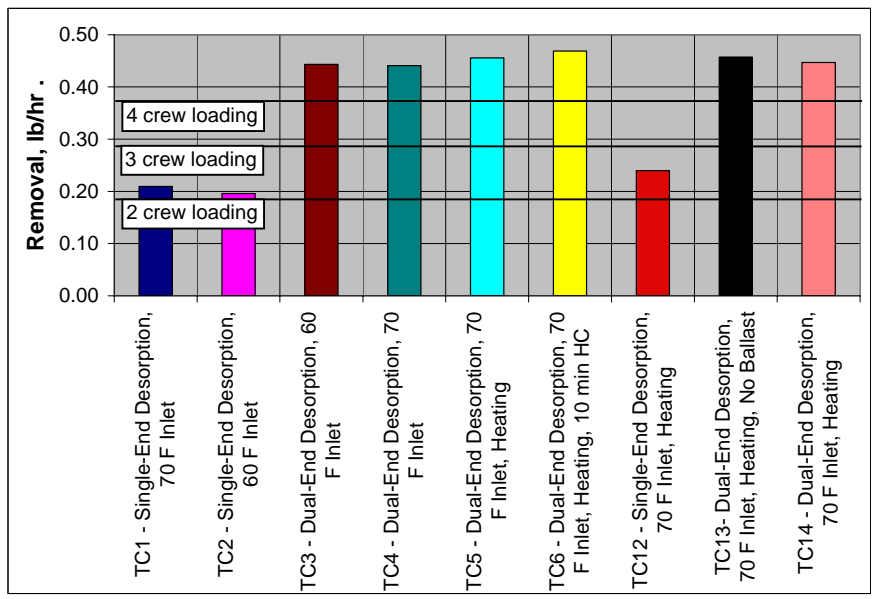

Figure 8 - Results for $\mathrm{CO}_{2} / \mathrm{H}_{2} \mathrm{O} \mathrm{P} 1$ Testing at 40 - 48 Hours Elapsed Time

P1 testing provided a wealth of useful information regarding the characteristics of $\mathrm{CO}_{2}$ and $\mathrm{H}_{2} \mathrm{O}$ removal in a VSA system. The understanding gained from this round of testing led to the next phase of design and testing discussed below.

\section{PHASE 2 DESCRIPTION}

The Phase 2 (P2) design was created to incorporate changes to increase performance and reduce mass based on lessons learned from P1 testing. Additionally, the P2 canister was designed to allow for easy changes to the material layering scheme, accommodate varying overall sorbent volumes up $8 \mathrm{~L}$ per bed. A vacuum sensor at the bed center was added to better understand desorption pressure gradients. Containment measures were incorporated to eliminate pellet liberation and minimize escapement of generated dust. The overall goal of P2 was to maximize the system performance within the confines of the bed by optimizing sorbent material layering, amounts, cycle times and valve timing events. A model of a two bed system containing P2 beds, 3 inch inlet valves, and 1.5 inch outlet valves is shown in the following figure.

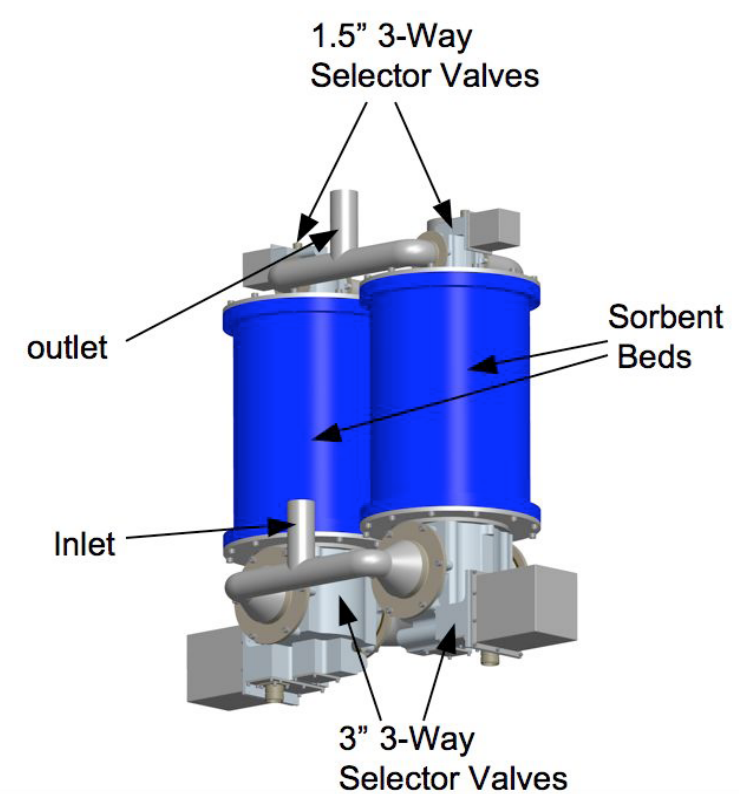

Figure 9 - Representation of a 2-Bed SBAR Phase 2 System

The cylindrical bed shape simplifies construction as well as sorbent retention design by allowing the use of circular o-rings. A cross section of the compression plate with o-ring seals is shown in Figure 10.

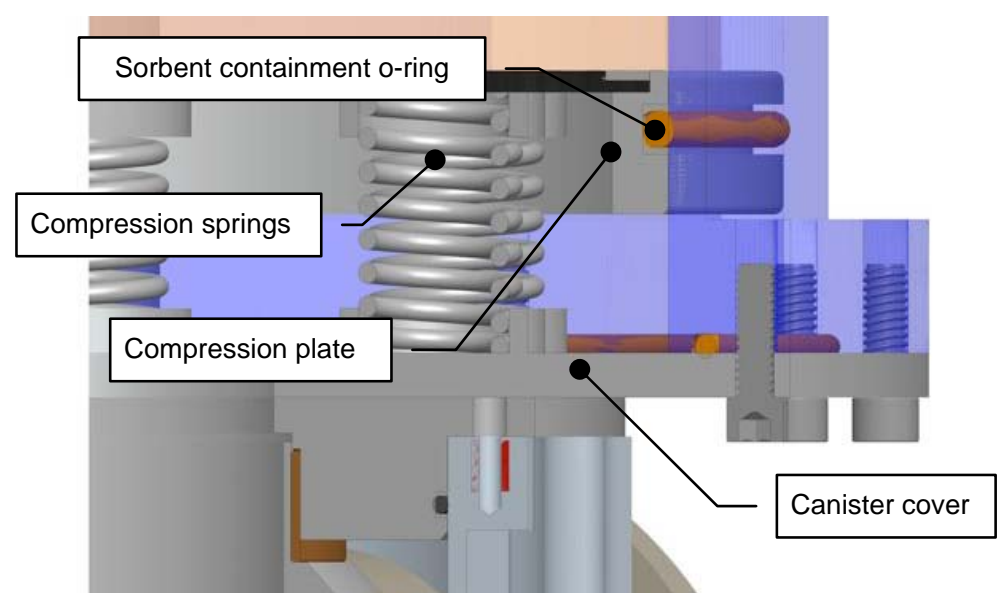

Figure 10 - Containment Baffle With O-Ring Seals

Sorbent layering schemes are based on adsorption studies and computer modeling performed at the University of South Carolina. The layering scheme for the first sorbent packing of the Phase 2 hardware, referred to as $\mathrm{P} 2 \mathrm{a}$, consisted of $50 \%$ silica gel, $17 \%$ $13 \mathrm{X}$, and $33 \% 5 \mathrm{~A}$. Based on $\mathrm{P} 2 \mathrm{a}$ test results, an alternate layering scheme was also testing. Denoted by $\mathrm{P} 2 \mathrm{~b}$, it consists of only zeolites $13 \mathrm{X}$ and $5 \mathrm{~A}$. The layering schemes are shown in Figure 11.

\section{PHASE 2 TEST RESULTS}

The phase 2 test article is shown below in Figure 12 . P2a testing employed the sorbent layering scheme of $50 \%, 17 \%$, and $33 \%$ of silica gel, zeolite $13 \mathrm{X}$, and zeolite $5 \mathrm{~A}$ respectively. Silica gel was chosen as the 
primary desiccant sorbent in this configuration because it has a high water capacity and since adsorption equilibrium data suggests it is able to release water easier than 13X.

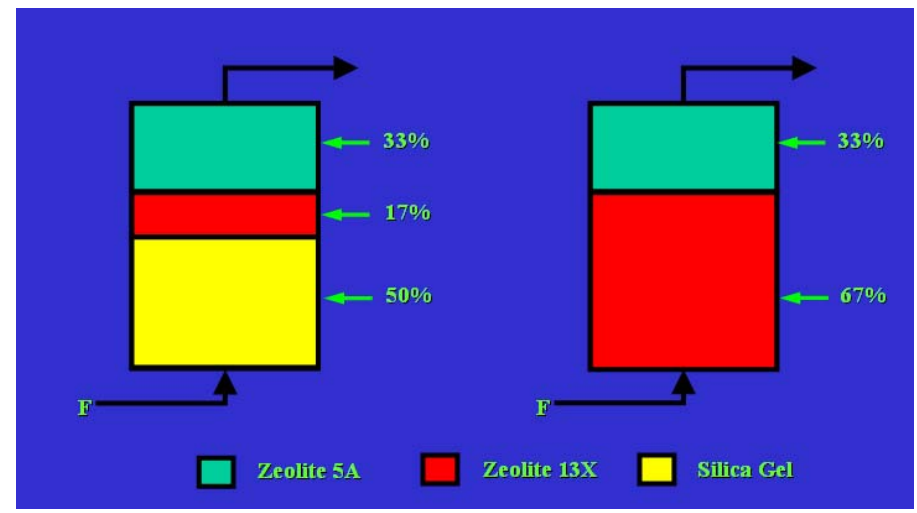

Figure 11 - Sorbent Layering Scheme for Phases 2a and 2b

A variety of tests were conducted on this configuration, including varying inlet $\mathrm{H} 2 \mathrm{O}$ and $\mathrm{CO} 2$ concentrations, flowrates, cycle times, and the fraction of the total desorption time that the bed was exposed to Dual Ended Desorption (DED). Results conclusively showed that DED for the entire desorption half cycle resulted in the best performance. Results of DED experiments are provided in Figure 13 below.

Other operational changes were made to obtain acceptable performance following the $>50 \%$ reduction in sorbent volume from the P1 bed at 18.9 liters to the $\mathrm{P} 2$ bed at 8.9 liters. The key operational change was to reduce the half cycle time from 15 minutes to 7.5 minutes. Performance with the P2 layering scheme was then sufficient to handle a 3 man loading of $\mathrm{CO}_{2}$.

Flowrate of the system is, for most cases, driven by water removal (vs. $\mathrm{CO}_{2}$ removal) requirements. The SBAR system removes $100 \%$ of the water from the process air stream, so the required flowrate is that which transports an amount of water into the system equal to the required removal rate. For nominal crew activity at a $50^{\circ} \mathrm{F}$ dew point, this translates to a flow rate of approximately 11 standard cubic feet per minute (scfm) and $14.5 \mathrm{scfm}$ to for 3 and 4 crewmembers respectively.

$\mathrm{CO}_{2}$ removal requirements must be met simultaneously with water removal. However, $\mathrm{CO}_{2}$ efficiency is always less than $100 \%$ and depends on many factors, including flowrate. As shown in Figure 14, the $\mathrm{CO}_{2}$ removal rate dropped below the 4 crew $\mathrm{CO}_{2}$ loading between 13.0 and $13.5 \mathrm{scfm}$, which is below the minimum 4 crew $\mathrm{H}_{2} \mathrm{O}$ loading flowrate of $14.5 \mathrm{scfm}$. At higher flowrates, measurements at the bed center showed large temperature swings in the silica gel desiccant. Higher temperatures reduce silica gel's working capacity and allow water to pass into the sorbent designated for $\mathrm{CO}_{2}$ removal, which reduces $\mathrm{CO}_{2}$ removal performance.

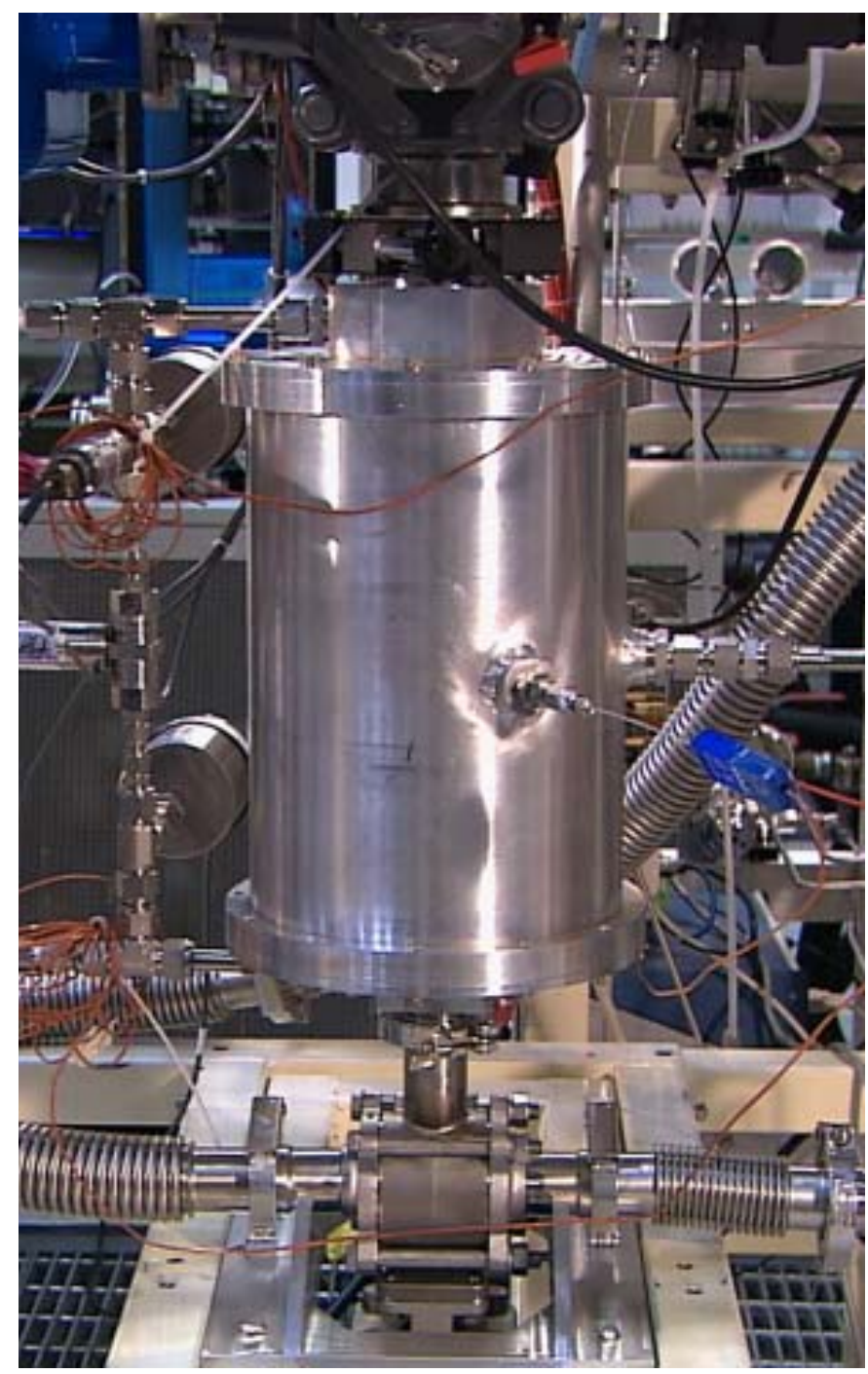

Figure 12 - Phase 2 Test Article

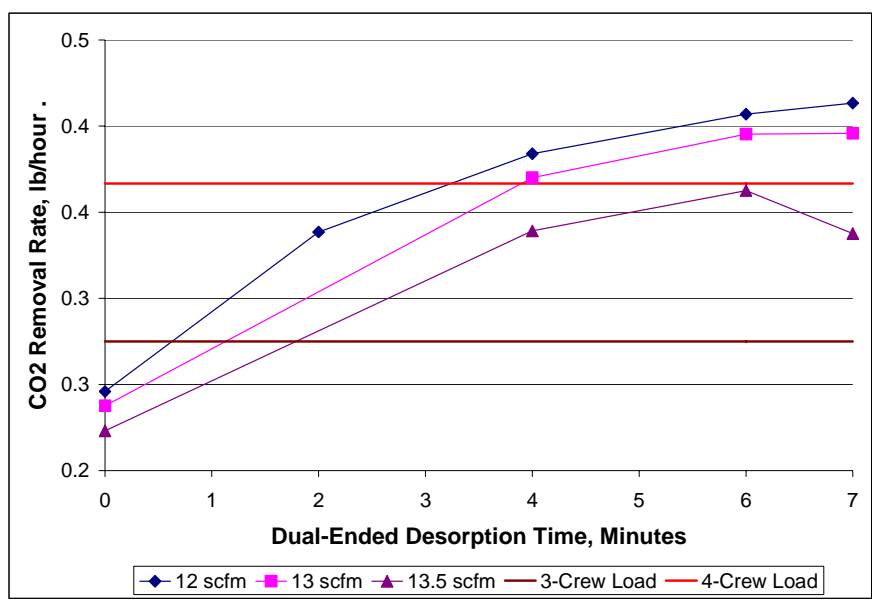

Figure $13-\mathrm{CO}_{2}$ Removal vs. DED Time in P2a Testing 


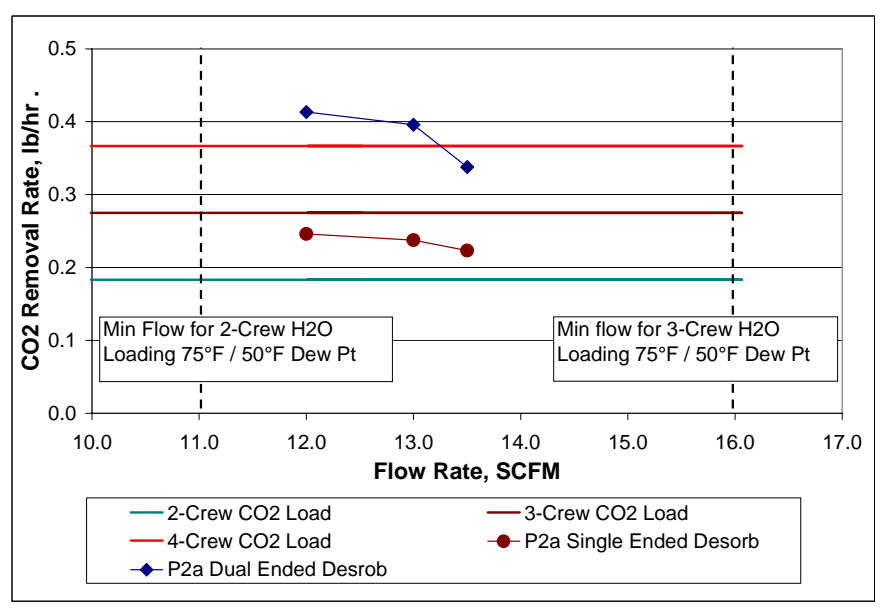

Figure 14 - Phase 2a Performance Data

The $\mathrm{CO}_{2}$ removal rate exceeded the nominal CEV 3crew loading for all dual-ended desorption cases. Water removal rate also exceeded the 2-crew requirement for all cases above shown.

To reduce the VSA temperature swings that limit working capacity, the bed layering scheme for the P2b bed configuration was altered by replacing the silica gel desiccant with zeolite 13X. Test results are discussed below.

\section{PHASE $2 b$ TEST RESULTS}

Silica gel, while having a higher loading capacity and propensity to desorb easier under vacuum than zeolite, also has the downside of not drying the process air stream to a dew point as low as zeolites. Additionally, the large temperature swings observed in the VSA process effectively limited its working capacity.

To account for this, an alternate layering scheme was tested in the Phase 2 canister, denoted as P2b. In this configuration, the silica gel was replaced with zeolite $13 \mathrm{X}$. The resulting layering was proportioned to match that of the Skylab 2-Bed Molecular Sieve system, which also used zeolite $13 \mathrm{X}$ and $5 \mathrm{~A}$ to remove $70 \%$ of the metabolic water and $100 \%$ of the metabolic $\mathrm{CO}_{2}$ for 3 crewmembers [8]. In the case of the SBAR system, $100 \%$ removal is required, thus the desiccant quantity was increased accordingly. Testing with the second layer scheme (P2a) began in March 2007.

Some results from the $\mathrm{P} 2 \mathrm{~b}$ testing compared with the P2a results are shown in Figure 15 below. From this data it is clear that the $\mathrm{P} 2 \mathrm{~b}$ layering configuration provides superior $\mathrm{CO}_{2}$ removal performance, which actually increased slightly with increasing flow rates. The removal rate tails off at the upper end of the plot, probably due to water creep after 16 days of operation without thermal regeneration.

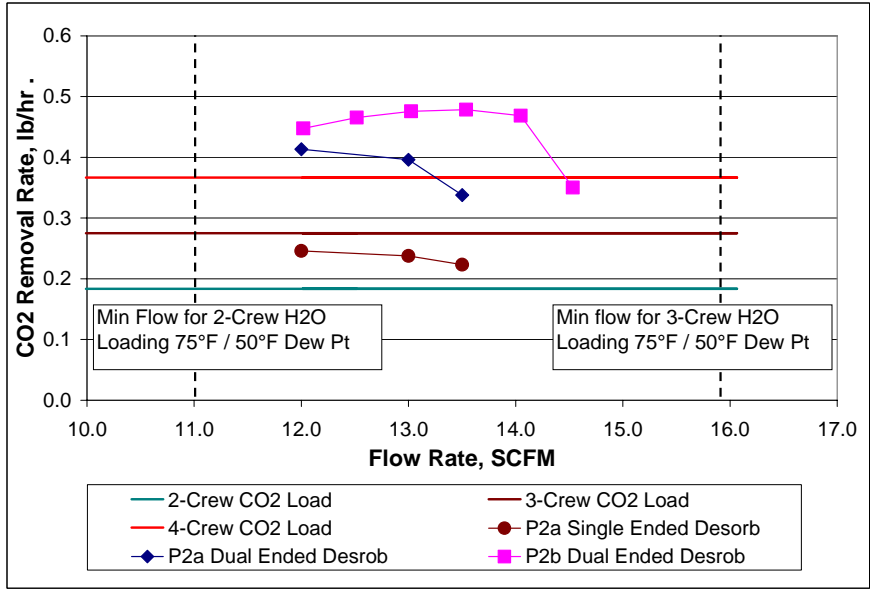

Figure 15 - Phase 2a vs. 2b Performance

\section{PHASE 3 SYSTEM DESCRIPTION}

The Phase 3 (P3) design, shown as a complete two-bed configuration in Figure 16 and as tested in Figure 17, incorporates the experience gained from the previously tested configurations. Two specific results have provided important feedback; (1) for certain operational conditions, water tends to slowly propagate down the bed in the flow direction and (2) providing additional vacuum access to the sorbent bed during desorption can have a dramatic effect on the removal performance.

Testing with both $\mathrm{P} 1$ and $\mathrm{P} 2$ demonstrated that a large increase in $\mathrm{CO}_{2}$ removal rate is obtained with dualended desorption. For P2 testing, the maximum observed increase in $\mathrm{CO}_{2}$ removal was $64 \%$. For $\mathrm{P} 1$ with $\mathrm{H}_{2} \mathrm{O}$ and $\mathrm{CO}_{2}$, the maximum increase was $110 \%$; the increase was much less for $\mathrm{P} 1$ with testing $\mathrm{CO}_{2}$ only at $28 \%$. The presence of water at the inlet during singleended vacuum desorption retards $\mathrm{CO}_{2}$ desorption occurring mainly at the outlet, so that cases which include $\mathrm{H}_{2} \mathrm{O}$ receive a greater advantage from opening the outlet end to vacuum.

Half-cycle time has also been shown to strongly influence $\mathrm{H}_{2} \mathrm{O}$ and $\mathrm{CO}_{2}$ removal performance in $\mathrm{P} 1$ and P2a testing. Although shorter half-cycle times can significantly increase performance, the interstitial and ullage air loss increases with decreasing half-cycle. Increasing the number of vacuum ports increases performance without incurring this penalty.

The P3 bed provides three locations for vacuum access, at the inlet, center, and outlet ports of the test article. The center port will provide an additional access to space for water desorption, increasing water removal performance, retarding propagation of water through the bed, and reducing the size and weight of the inlet vacuum line and valves. Testing will be performed with P3 to determine how long the middle port should remain open during desorption to ensure that counter-current desorption (in the reverse direction of the adsorption flow) is the dominant desorption mode. 


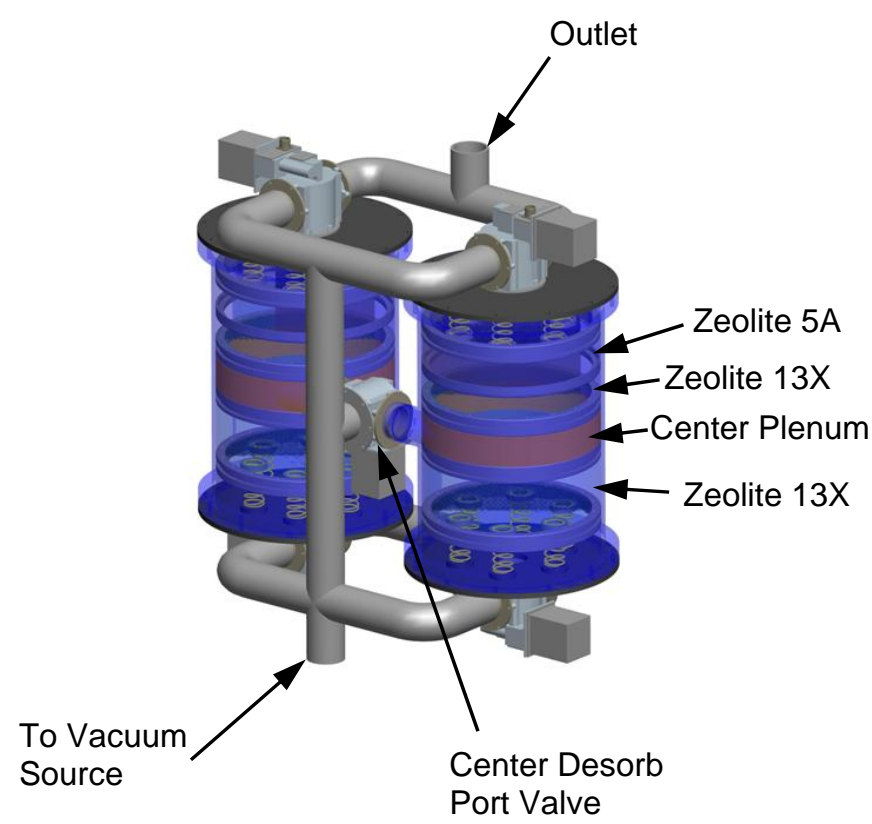

Figure 16 - SBAR P3 System

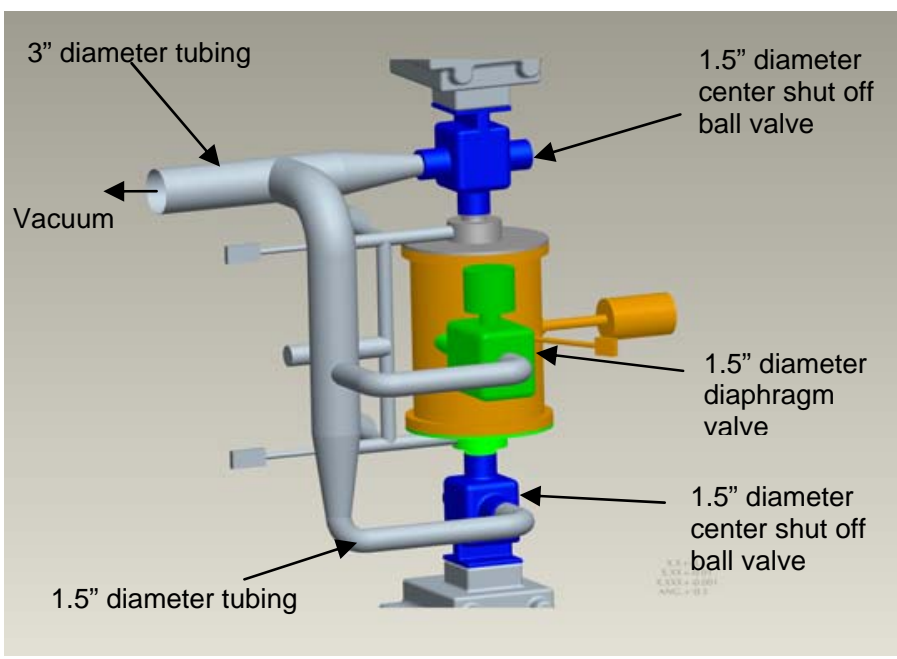

Figure 17 - SBAR Prototype 3 Test Article

By increasing the number of vacuum ports, the overall port size can be reduced, therefore reducing the 3" inlet valves to only 1.5 inches. This provides an estimated valve weight savings of $12 \mathrm{lbs}$ for the bed. Additionally, the extra port to vacuum lowers the average bed pressure during desorption, resulting in lower residual loading and increasing the sorbent's cyclic working capacity. Computer simulation results of the pressure gradient through the bed for dual and triple port desorption are shown in Figure 18. The x-axis is fraction of bed length, or $\mathrm{z} / \mathrm{L}$. Although overall lowest bed pressure is achieved with the in bed port location near the axial center $(z / l=0.45)$, greater water removal will be achieved with the third port nearer to the bed entrance.

\section{PHASE 3 TEST RESULTS}

The P3 test article, containing 6.2L of sorbent and three ports to vacuum is shown in Figure 19 below.

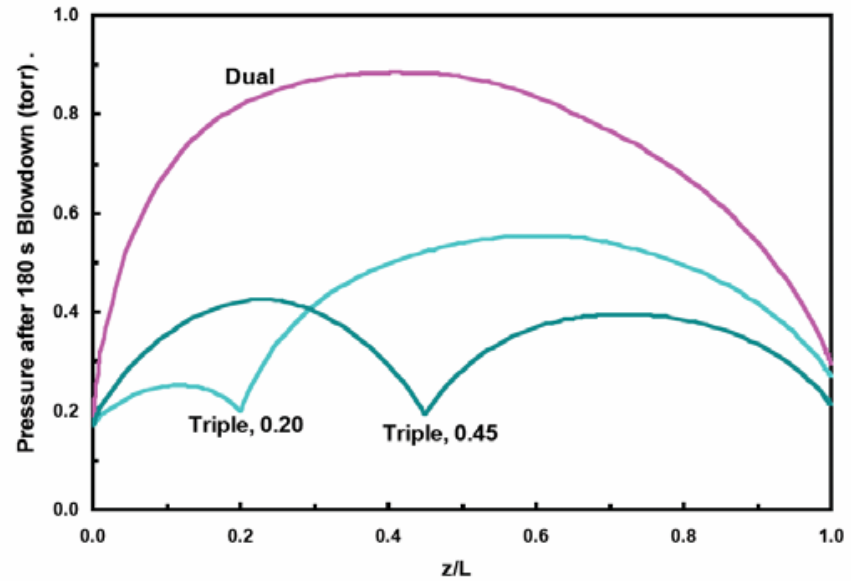

Figure 18 - Pressure Gradient under Vacuum, Port Effects

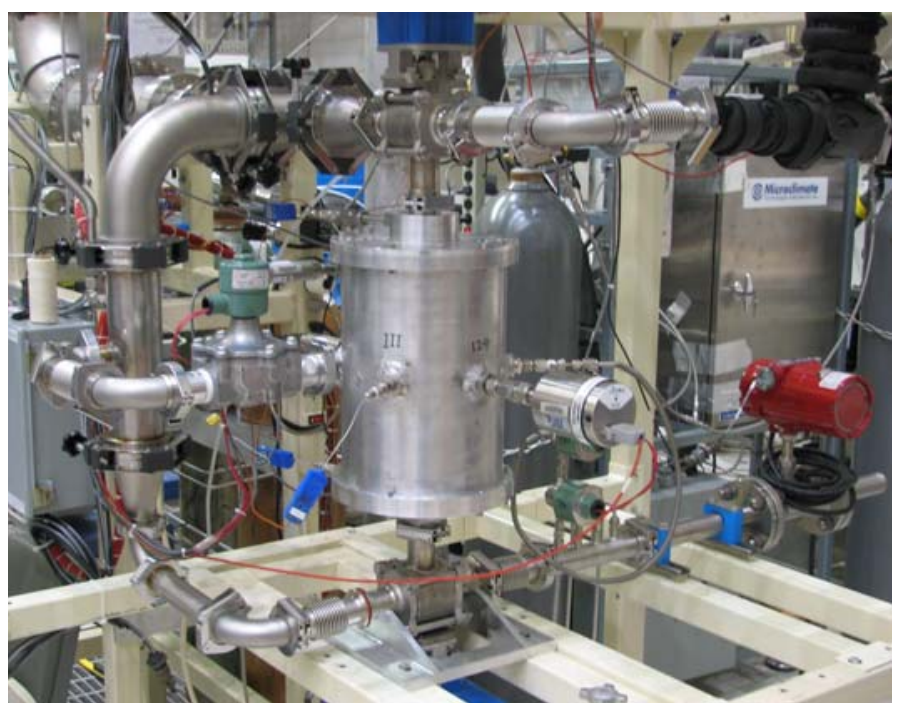

Figure 19 - P3 Test Article

Amendments to Orion's atmosphere requirements that occurred between P2 and P3 testing levied new operational requirements, specifically, the requirement to accommodate operation in an $80^{\circ} \mathrm{F}$ cabin temperature and a $45^{\circ} \mathrm{F}$ dew point. The combination of low relative humidity and higher metabolic loading associated with these operating parameters significantly increased the flowrate requirement. Shown in Figure 20 are test results at the worst case operating conditions of $80^{\circ} \mathrm{F}$ drybulb and $45^{\circ} \mathrm{F}$ dewpoint.

Comparing the conditions of the P2 testing (Figure 15), it is evident that that the flowrate through the bed is much higher for P3. Figure 20 shows that, with a 3-crew $\mathrm{H}_{2} \mathrm{O}$ metabolic loading and $20 \mathrm{scfm}$ flowrate, the P3 system was able to remove the $\mathrm{CO}_{2}$ equivalent of 4-crew. This substantial increase in flowrate over the P2 testing was a direct consequence of the much higher water loading for worst case conditions. Time constraints have only allowed testing of the P3 article under these worse case conditions. Future testing is planned to evaluate the system performance at lower loading conditions similar 
to P2 testing to generate test data for the full range of operations. A correlation tool described in the following section will be used to estimate the performance until actual data becomes available.

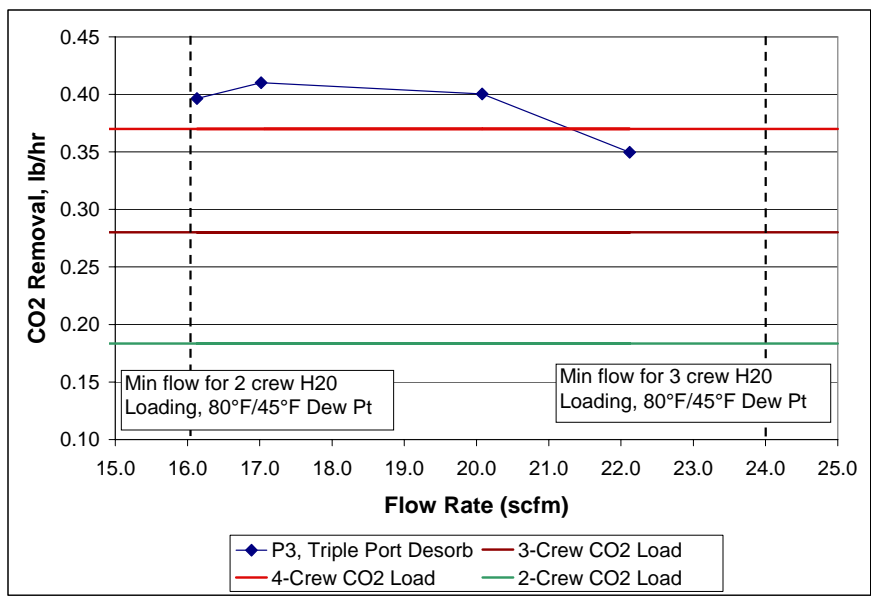

Figure 20 - P3 Performance Data

\section{MATHEMATICAL MODELING AND COMPUTER SIMULATION}

\section{FINITE DIFFERENCE VSA (FD VSA) MODEL}

An important facet of the SBAR program is the development and utilization of mathematical models and computer simulations, providing greater understanding of the physical process, and as a result, guidance in the SBAR sorbent bed design. This work is being performed by the University of South Carolina and is described in details in prior publications [3, 4, 5]. Studies on single gas and mixed gas adsorption and mass transfer studies of $\mathrm{H}_{2} \mathrm{O}, \mathrm{CO}_{2}, \mathrm{~N}_{2}$, and $\mathrm{O}_{2}$ on zeolites $13 \mathrm{X}, 5 \mathrm{~A}$, and silica gel are being performed at Vanderbilt University [9]. The computer tool has the capability to simulate adsorption of all principle gases, heat transfer, and vacuum desorption of silica gel, zeolite $13 \mathrm{X}$ and zeolite $5 \mathrm{~A}$. Studies completed and in progress analyze the dependence of performance on many parameters, including;

- Vacuum pressure

- Adsorbent layering (order and relative quantities)

- Cycle time

- Metabolic loading

- Process air flow rate

- Isothermal vs. adiabatic operation

- Silica gel mass transfer coefficient (unavailable empirically)

\section{RESULTS OF THE FD VSA SIMULATIONS}

Computer simulations have helped to guide the SBAR for Orion development path. The model has successfully simulated VSA operations of single, dual and triple vacuum port systems (see for example Figure 18), and has been instrumental when determine the next phase configurations. The complex high velocity, low density gas analysis has also provided an understanding of how the SBAR responds to transient metabolic profiles, sweep gas desorption, and the contribution of adsorbed $\mathrm{N}_{2}$ and $\mathrm{O}_{2}$ to the ullage gas overboard losses.

\section{SBAR SYSTEM SIZING TOOL}

Interpolation of actual test performance via correlation equations provides another valuable method for system sizing and optimization, though it is limited to hardware configurations within the existing range of tested conditions. Such a tool was developed to for rapid determination of equivalent system mass, or ESM, for a wide range of potential ISS and lunar CEV mission profiles.

Figure 21 provides the test data from Phase $2 b$ (8.9 liter bed), $3 a$ (4.5 liter bed), and $3 b$ ( 6.2 liter bed) in the form of removal fraction as a function of volumetric flow rate. The results of the correlation equation are shown superimposed on the test data. With only a few exceptions, the correlation provides a close fit to the test data, despite the variances in flow rate (9 to $22 \mathrm{scfm}$ ), bed volume, inlet $\mathrm{CO}_{2}$ partial pressure (3 to 7 torr), half cycle time (3 to 6 minutes), and inlet dewpoint (45 to $60^{\circ} \mathrm{F}$ ). All removal fractions are recorded at an elapsed run time of 24 hours.

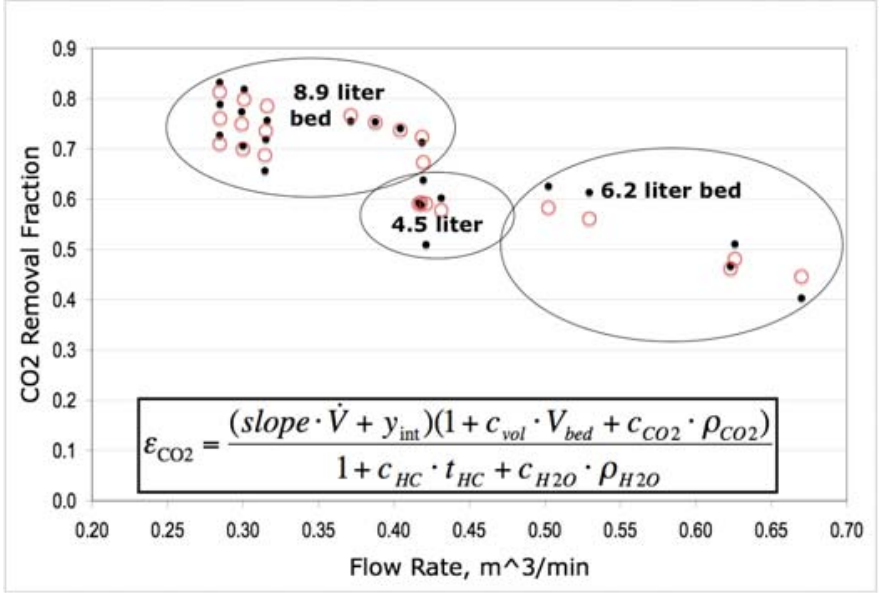

Figure 21 - Calculated and Actual $\mathrm{CO}_{2}$ Removal Fraction vs. Inlet Flow Rate. Filled dots are test data; open circles are predictions.

As testing progressed, it was noted that, especially for smaller bed volume and higher flow rates, $\mathrm{CO}_{2}$ removal performance decreased over time. This is a concern since $\mathrm{CO}_{2}$ removal performance at the end of the mission must be sufficient to maintain the crew atmosphere below maximum $\mathrm{CO}_{2}$ partial pressures. The reduction in $\mathrm{CO}_{2}$ removal performance over 5 days for a subset of test cases is provided in Figure 22. In this plot, the $x$-axis is the amount of water adsorbed per half cycle per bed volume in the units of mole of water per liter of adsorbent. This unit was chosen since the reduction in 
$\mathrm{CO}_{2}$ removal is due to the migration of water through the zeolite bed.

The correlation data for reduction in $\mathrm{CO}_{2}$ removal is also shown in the plot. The correlation is less accurate than the removal fraction correlation; however it will be shown in subsequent figures that it is sufficient to provide a reasonable and generally conservative prediction of long-term system performance.

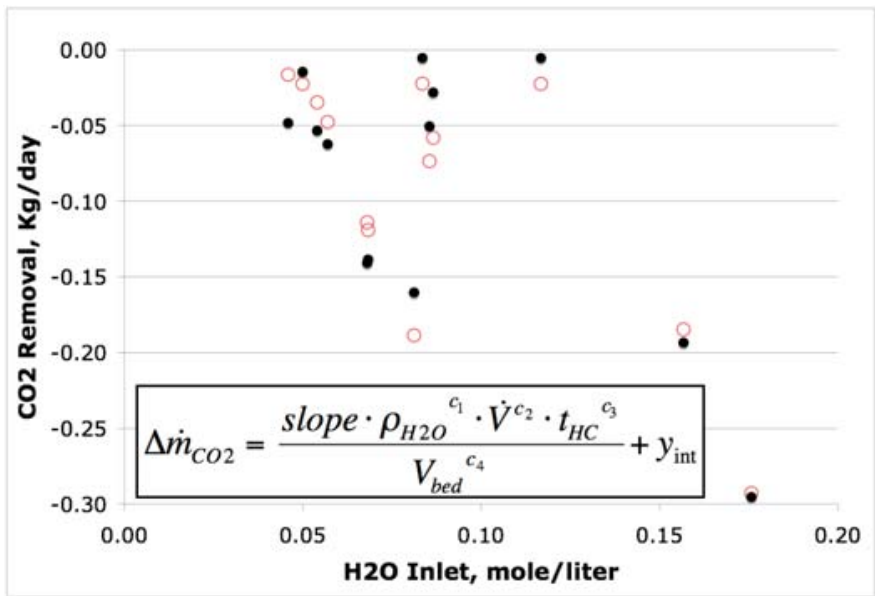

Figure 22 - Calculated and Actual $\mathrm{CO}_{2}$ Removal Rate vs. Inlet $\mathrm{H}_{2} \mathrm{O}$. Filled dots are test data; open circles are predictions.

Figure 23 provides a long-term prediction based on the two correlations above for an 8.9 liter bed operated at 3 different inlet $\mathrm{CO}_{2}$ partial pressures. The prediction is shown as a line; also shown as points are the actual removal rates from Phase $2 \mathrm{~b}$ testing. Comparing the prediction and test data, it is evident that (1) the prediction provides a reasonable approximation, and (2) the prediction gives a conservative estimate of end-ofmission $\mathrm{CO}_{2}$ removal rate.

The comparison between test data and prediction is repeated for a 6.2 liter bed in Figure 24 and for a 4.5 liter bed in Figure 25. A more dramatic reduction in $\mathrm{CO}_{2}$ removal is observed; this is the result of both decreased bed volume for the 4.5 and 6.2 liter bed test cases and increased flow rates in the 6.2 liter bed test cases. The 6.2 liter bed test cases were run for worst case conditions of six crew at the upper selectable cabin temperature, which results in high metabolic water loading. In all but two of these cases, the prediction for the end-of-mission $\mathrm{CO}_{2}$ removal rate is slighter lower than the test result. The correlation method has thus been verified to be generally conservative and of reasonable accuracy for a wide range of inlet and operating conditions and bed volumes. In the following analyses, the correlation will be used to predict required bed size and operating conditions (cycle time and flowrate) for various mission scenarios.

Results from an example application of the correlations are shown in Figure 26. Here, the CEV mission scenario where 6 crewmembers are transported to the ISS is analyzed. Metabolic rates are based on the
Constellation Program Human Systems Integration Requirements [10]. For nominal crew activity, the total heat output rate is $474 \mathrm{btu} / \mathrm{hr}$. Cabin temperature and dewpoint is set at $70^{\circ} \mathrm{F}$ and $50^{\circ} \mathrm{F}$ respectively; two of the three on-board SBAR systems are assumed operational.

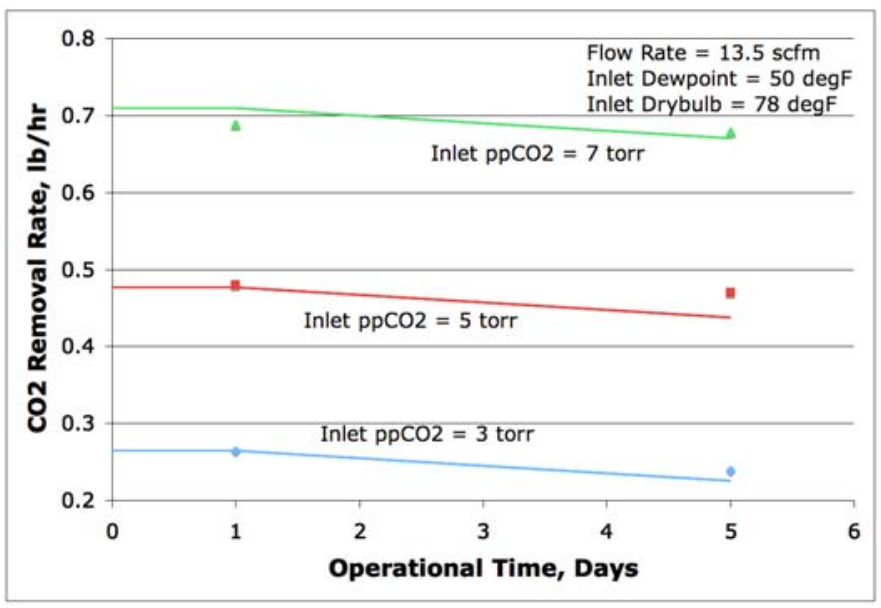

Figure 23 - Calculated and Actual CO2 Removal Rate vs. Operating Time for a 8.9 liter bed

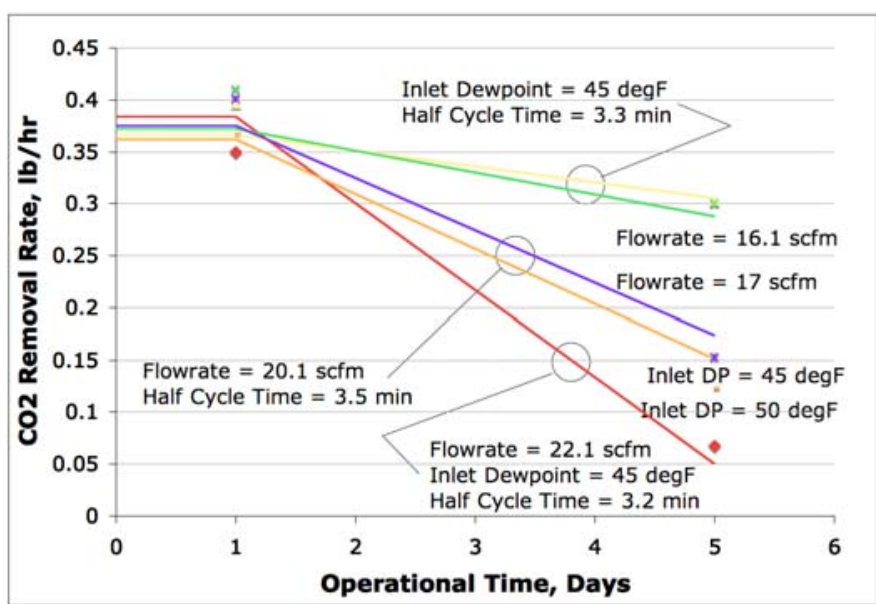

Figure 24 - Calculated and Actual $\mathrm{CO}_{2}$ Removal Rate vs. Operating Time for a 6.2 liter bed

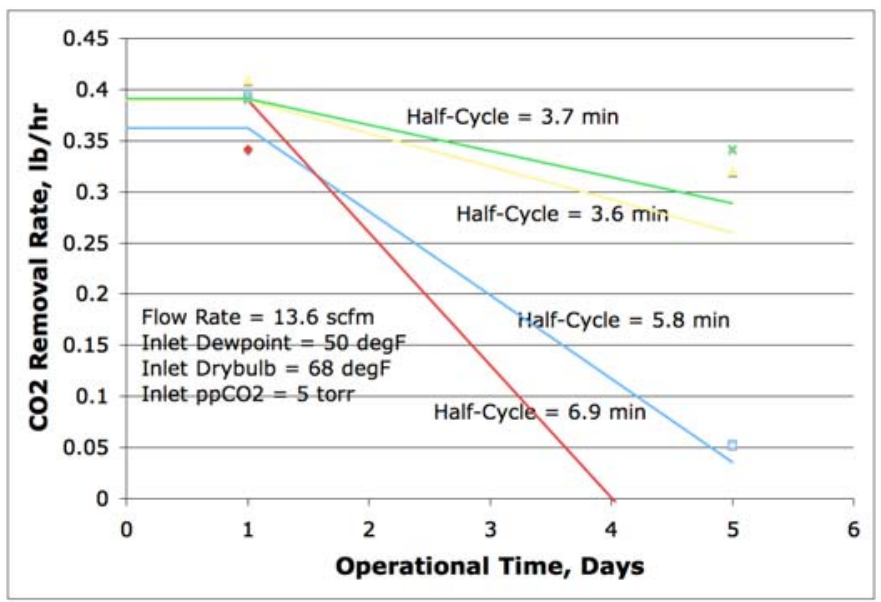

Figure 25 - Calculated and Actual $\mathrm{CO}_{2}$ Removal Rate vs. Operating Time for a 4.5 liter bed 
In Figure 26, the bed volume is varied from 4.5 to 9 liters and the half-cycle time is varied from 3 to 6 minutes. System flow rate is set to that required for $\mathrm{CO}_{2}$ or $\mathrm{H}_{2} \mathrm{O}$ removal, depending on which is greater. The wave-like trend illustrates that, for any particular bed volume, equivalent system mass (ESM) is lower for higher half cycle time due to less gas loss. For cases where $\mathrm{CO}_{2}$ removal requirements are not met, the result is not shown (thus the "missing" columns).

The conclusion of this study is that minimum ESM of 55 $\mathrm{Kg}$ is attained for two conditions: a bed volume of 4.5 liters and half cycle time of 4 minutes, and a bed volume of 5 liters and half-cycle time of 4.5 minutes.

This analytical tool is being used to determine the minimum required bed size for all projected mission scenarios and corresponding operating conditions.

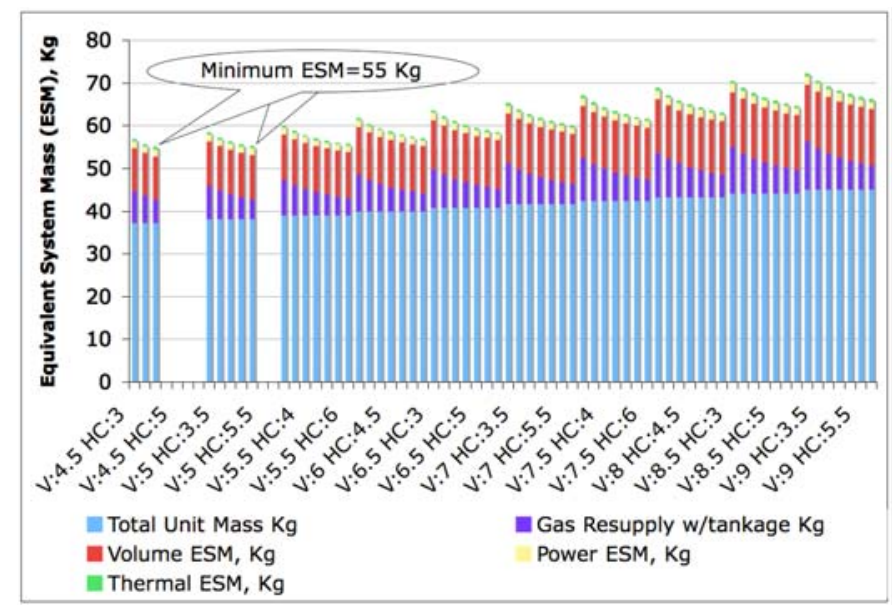

Figure 26 - Results of Parametric Study to Determine Minimum Equivalent System Mass with Variations in Bed Volume and Cycle Time.

\section{NEXT PHASE (P4)}

A configuration for a P4 system is under design. This design will retain the overall operation of the P3 system, but incorporate a new valving technique that utilizes the system vacuum manifold to house shuttle valves. A model representation of such a system is shown below in Figure 27. The weight savings of this concept comes from reducing the total number of actuators from six to three, reducing moving parts, and allowing for lighter weight materials in place of the metal ball valve components. This configuration would also incorporate a simplified seal design.

\section{SUMMARY}

Marshall Space Flight Center has embarked on an aggressive and comprehensive program in order to provide an accurate assessment of the potential of adsorbents for removal of all metabolic water and carbon dioxide on the crew exploration vehicle.
Significant progress has been made toward this objective.

A full-scale test stand was completed and testing performed on three prototype packed canisters. $\mathrm{CO}_{2}$ and $\mathrm{H}_{2} \mathrm{O}$ removal performance was substantially improved via the adjustment of process control parameters such as adsorbent selection and quantity, vacuum port location and sizing, and cycle time. Additionally, the need for periodic thermal regeneration has been eliminated in the 8.9L bed for missions of approximately two weeks in length (Figure 14). Design modifications have been implemented in Phases 1 through 3 to substantially reduce system mass, and Phase 4 is in preparation to further reduce weight (Figure 28). Additional testing is planned for the P3 system to evaluate the system under simulated suit loop conditions to include low pressure operations and to evaluate the system under metabolic transient conditions.

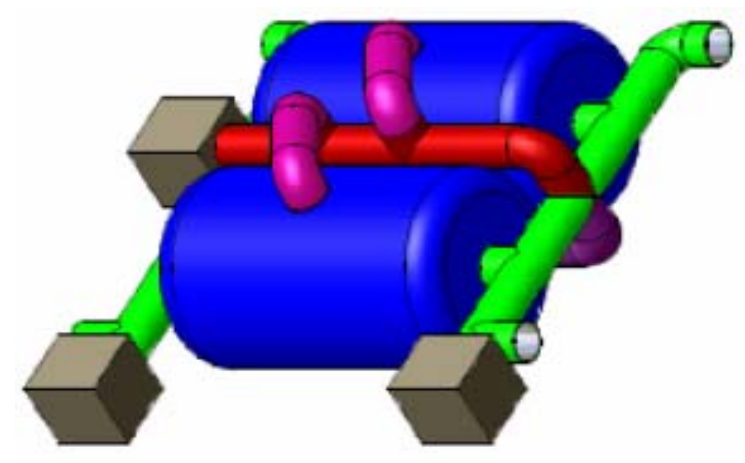

Figure 27 - SBAR P4 Concept

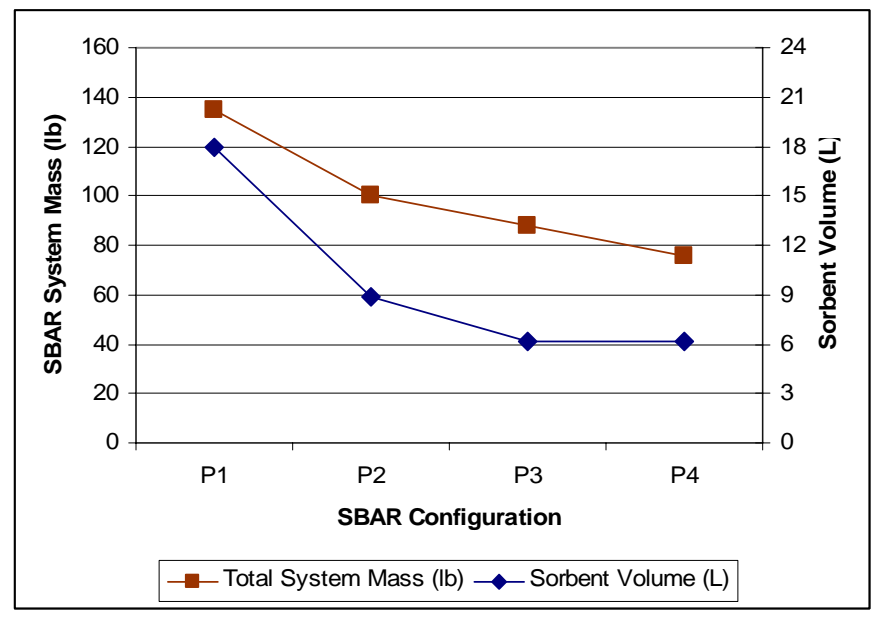

Figure 28 - Development Size and Weight Reductions

\section{CONCLUSIONS}

The Sorbent-Based Atmosphere Revitalization program has successfully demonstrated the viability of physical adsorbents for application on the Orion crew capsule, as well as on future vehicles with similar architectures such as the Altair lunar lander. Significant weight reductions 
have been realized over three design and test phases. Design is underway for the next phase, which will further reduce system mass and advance the SBAR technology readiness level. 


\section{REFERENCES}

1 Lewis, John et. al., "Crew Exploration Vehicle Environmental Control and Life Support Development Status", 2007-013044 SAE International, Chicago, 2007

2 Ruthven, Douglas M., Principles of Adsorption and Adsorption Processes, John Wiley and Sons, 1984

3 Reynolds, Steven P., Ebner, Armin D. and Ritter, James A., Knox, James C., and LeVan, M. Douglas, "Mathematical Simulation of the Sorbent-Based Atmosphere Revitalization System for the Crew Exploration Vehicle", 2006-01-2220 SAE International, Norfolk, Virginia, 2006

4 Ritter, James A., Reynolds, Steven P., Ebner, Armin D., Knox, James C., and LeVan, M. Douglas, "Design and Performance of the Sorbent-Based Atmosphere Revitalization System for Orion", 2007-01-3070 SAE International, Chicago, 2007

5 Ritter, James A., Ebner, Armin D. "Design of an Adsorption-Based Carbon Dioxide, Humidity and Trace Contaminant Removal System," Draft Report Submitted to Marshall Space Flight Center, May 2007

6 Yu Wang and M. Douglas LeVan, "Pure and Binary Adsorption Equilibria of Water Vapor and Carbon Dioxide on Zeolites," J. Chem. Eng. Data, in preparation

7 Knox, James C., Howard, David, and Perry, Jay, "Engineered Structured Sorbents for the Adsorption of Carbon Dioxide and Water Vapor from Manned Spacecraft Atmospheres: Applications and Modeling," 2008-01-2094 SAE International, San Francisco, 2008

8 Hopson, George C., "Skylab Life Support and Habitability System Requirements and Implementation", $22^{\text {nd }}$ International Astronautical Congress, Brussels, 1971

9 Yu Wang and M. Douglas LeVan, "Pure and Binary Adsorption Equilibria of Water Vapor and Carbon Dioxide on Zeolites," J. Chem. Eng. Data, in preparation

10 "Constellation Program Human-Systems Integration Requirements", CxP 70024, Baseline Edition, Appendix E, 2006 